Acta Zoológica Mexicana (n.s.) 23(1): 47-51 (2007)

\title{
DESCRIPCIÓN DE UNA ESPECIE NUEVA DE CREUGAS THORELL (ARANEAE: CORINNIDAE) DE LA PENÍNSULA DE BAJA CALIFORNIA, MÉXICO
}

\author{
María Luisa JiMÉnEZ \\ Laboratorio de Aracnología y Entomología. Centro de Investigaciones Biológicas del \\ Noroeste (CIBNOR) Apdo. Postal 128, La Paz, B.C.S., 23090, MÉXICO \\ ljimenez04@cibnor.mx \\ RESUMEN
}

Se describe e ilustra una nueva especie de araña corredora Creugas comondensis sp. nov. basada en especimenes colectados en oasis del estado de Baja California Sur.

Palabras Clave: Creugas comondensis, nueva especie, oasis, Corinnidae, Baja California.

\section{ABSTRACT}

A new species of running spider, collected in oases of Baja California Sur is described and illustrated. Key Words: Creugas comondensis, new species, oases, Corinnidae, Baja California.

\section{INTRODUCCIÓN}

El género Creugas Thorell 1878 de origen americano, se encuentra actualmente incluido en la familia Corinnidae, y junto con los géneros Falconina Brignoli 1985, Megalostrata Karsch 1880, Septentrinna Bonaldo 2000 y Xeropigo O. Pickard-Cambridge 1882 conforman la subfamilia Corinninae (Bonaldo 2000 y Ubick \& Richman en: Ubick et al. 2005). El género Creugas actualmente agrupa a 18 especies que con excepción de C. gulosus, están distribuidas desde Estados Unidos hasta Centro y Sudamérica. De México se registran once especies: C. annamae (Gertsch \& Davis 1940), C. navus (F.O.P. Cambridge, 1899), C. bicuspis (F.O.P. Cambridge 1899), C. falculus (F. O. P. Cambridge 1899) y C. uncatus (F.O.P. Cambridge, 1899) del estado de Guerrero (PickardCambridge, 1899), C. bajulus (Gertsch 1942) de Baja California, C. gulosus Thorell, 1878 de Nuevo León, Sinaloa, San Luis Potosí, Querétaro, Distrito Federal y Colima, C. epicureanus (Chamberlin 1924) de Sonora, C. cinnamius Simon, 1888 de Morelos, C. nigricans (C.L. Koch 1841) y C. praeceps (F.O.P. Cambridge 1899) sin localidad específica pues sólo se citan de México (Bonaldo 2000 y Platnick 2006). De la península de Baja California sólo $C$. bajulus y C. gulosus han sido registradas. La primera es una especie nativa de la región que se distribuye desde California, Estados Unidos, hasta el norte de Baja California y la segunda es cosmotropical registrada en América, Africa, Sureste de Asia y la Polinesia (Bonaldo 2000; Ubick \& Richman en: Ubick et al. 2005). 
El género Creugas se caracteriza por agrupar arañas de tamaño mediano (5.4 -14.8 $\mathrm{mm}$ ), con la región cefálica poco delimitada y presentar un clípeo corto. La apófisis retrolateral tibial del pedipalpo del macho es bilobulada, con un proceso ventral retrolateral y un proceso cimbial basal retrolateral; el conducto espermático es poco espiralado y en forma de "S", restringido a la parte basal del bulbo; el émbolo está modificado, con un proceso embolar o con una división apical. El epiginio con dos aberturas copuladoras pequeñas posteriores o una abertura grande anterior. (Bonaldo 2000).

Muy poco se sabe sobre la biología de estas arañas, pues sólo se menciona que se han encontrado bajo rocas (Gerstch 1942). En este trabajo se describe por primera vez una especie nueva del género Creugas capturada en dos oasis de la parte media de la península de Baja California.

\section{MATERIAL Y MÉTODOS}

Ejemplares machos y hembras fueron capturados por medio de trampas de caída, a través de tres transectos lineales de $150 \mathrm{~m}$ cada uno, entre la vegetación mésica y xérica de los poblados San Isidro-La Purísima y San José de Comondú, Baja California Sur, durante el ciclo anual del 2002-2003. Ambos sitios están localizados en un ambiente desértico con un clima subtropical muy seco (BWh) (García 1981). Para determinar la especie, los genitales de ambos sexos fueron extraídos y examinados bajo un microscopio estereoscópico Zeiss, sumergidos en alcohol al $70 \%$. Las medidas (en $\mathrm{mm}$ ) de la descripción de la especie, fueron tomadas usando una regleta micrométrica ocular siguiendo el formato de Bonaldo (2000). Las abreviaturas usadas en el texto y figuras fueron las siguientes: OMP ojos medios posteriores; OLP ojos laterales posteriores; OMA ojos medios anteriores; OLA ojos laterales anteriores; $\mathrm{PCr}$ proceso cimbial basal retrolateral; DAC división apical del émbolo; PRE porción retrolateral del émbolo, ATR apófisis tibial retrolateral; PV proceso ventral de la apófisis tibial retrolateral; ST subtégulo; C conductor; CNAN Colección Nacional de Arácnidos, Instituto de Biología, Universidad Nacional Autónoma de México; CAS California Academy of Sciences; CARCIB Colección de Insectos y Arácnidos del Centro de Investigaciones Biológicas del Noroeste. Los genitales fueron aclarados con ácido láctico previo a la realización de las ilustraciones, a través de una cámara clara con aumentos de $5 x$.

\section{RESULTADOS}

\section{Creugas comondensis Jiménez sp. nov.}

Holotipo macho - Longitud total 6.8. Caparazón 2.8 ancho y 3.6 largo, altura 1.2; altura del clípeo 0.15 . Fila anterior de los ojos 0.8 , fila posterior 1.05 ; diámetros de los ojos OMA 0.16 , OLA 0.19, OMP 0.13, OLP 0.16; distancia entre los ojos: OMA-OMA 0.09, OMA-OLA 0.03, OMPOMP 0.13, OMP-OLP 0.23, OLA-OLP 0.03. Quelíceros 1.8, retromárgen con 5 dientes iguales. 
Esternón 2.3. Opistosoma 3.6. Fórmula de las patas 4123 . I - fémur 3.5/patela 1.5/tibia 3.8/ metatarso 3.1/tarso 2.2/longitud total 14.2; II - 3.6/1.6/3.0/3.0/2.0/13.2; III - 3.2/1.5/2.6/3.0/1.7/ 12.1; IV - 4.3/1.6/4.3/4.5/2.1/17.0. Espinas: I - fémur d1-1, p0-1-1; tibia v2-2-2-2-2-1; metatarso v2-2. II - fémur d1; p1-1; tibia v2-2-2-2; metatarso v2-2. III - fémur d1-1-1; r1-1; p1-1; tibia v2-22; r1-1; p1-1; metatarso v1-1, r1-1-1; p1-1-1. IV - fémur d1-1-1; p1-1, r1; tibia v2-2-2; p1-1; r1-1; metatarso $v 1-1-1 ; \mathrm{p} 1-1-1 ; \mathrm{r} 1-1-1$.

Caparazón café, cubierto con pelos cortos simples, plumosos y hialinos, región cefálica poco delimitada, más oscura sobre todo en la región ocular, poco hirsuto, surco torácico bien
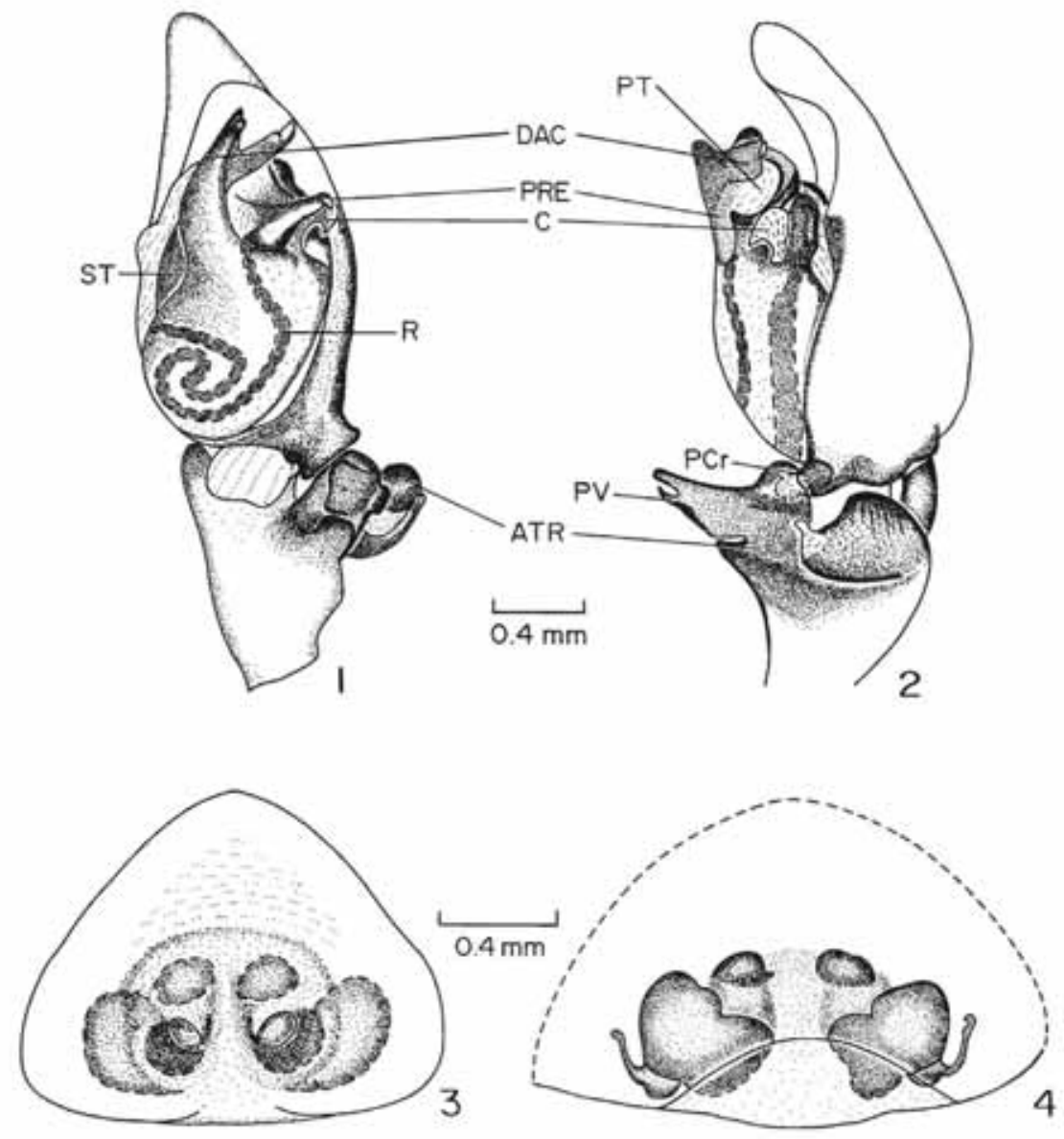

Figuras 1-4

Creugas comondu, sp. nov. Macho 1) vista ventral del pedipalpo, 2) vista lateral del pedipalpo. Hembra 3) vista ventral del epiginio, 4) vista dorsal del epiginio. DAC, división apical del émbolo; PT, proceso tegular; $\mathrm{ST}$, subtégulo; PRE, porción retrolateral del émbolo; $\mathrm{C}$, conductor; $\mathrm{R}$, conducto espermático; $\mathrm{PCr}$, proceso cimbial basal retrolateral; PV, proceso ventral de la apófisis tibial retrolateral; ATR, apófisis tibial retrolateral. 
delimitado y poco profundo. Hilera de ojos anteriores casi recta, ojos medios anteriores aperlados, ligeramente más pequeños que los laterales; hilera de ojos posteriores ligeramente procurvada, ojos medios posteriores más pequeños y más cercanos entre sí que a los ojos laterales. Quelíceros dorsalmente robustos, oscuros y muy pilosos, dedo móvil café oscuro; esternón y enditos cafés, éstos últimos convergentes, labio más largo que ancho y a la mitad del tamaño de los enditos, muy piloso en el borde anterior. Esternón con escasos pelos negros. Patas amarillas y largas, poco robustas, muy pilosas y con escasas sedas plumosas. Opistosoma piloso con sedas largas, con escudo dorsal 1/3 de su largo y sin escudo ventral. Tibia del pedipalpo un poco más ancha que la mitad del cimbio, ATR bilobulada, el lóbulo ventral con un proceso ventral corto (PV), lóbulo dorsal cóncavo en vista ventral. Cimbio con un PCr conspicuo; el ST es pequeño; conducto espérmatico $(R)$ corto, en forma de "S" y curvo en lado proximal, conductor hialino (C); DAC del émbolo es extremadamente desarrollada, formando una lamela acanalada, que ocupa todo el ápice del tégulo. El émbolo es continuo con el PT y su porción retrolateral es curva (Fig. 1). Hembra - Longitud total 8.6. Caparazón 3.3 ancho y 4.2 largo, altura 1.15; altura del clípeo 0.2. Fila anterior de ojos 1.0, fila posterior 1.3; diámetros: OMA 0.19, OLA 0.19, OMP 0.13, OLP 0.19; distancia entre los ojos: OMA-OMA 0.13; OMA-OLA 0.09, OMP-OMP 0.23; OMP-OLP 0.29, OLA-OLP 0.03. Quelíceros 2.05. Esternón 2.3. Opistosoma 4.4. Patas. I - fémur 3.7/patela 1.8/ tibia 3.6/metatarso/3.0/tarso 2.3/total 14.4; II - 3.3/1.6/3.6/2.7/2.0/13.2; III - 3.1/1.3/2.6/2.6/ 1.8/11.4; IV - 4.0/1.6/4.0/3.8/2.2/15.6. Espina de las patas: I - fémur d1-1; p1; tibia v2-2-2-2-2; metatarso v2-2; II - fémur d1-1; p1-1; tibia v2-2-2-2; metatarso v2-2; III - fémur d1-1; p1-1; tibia v2-2-2; metatarso v2-2; IV - fémur d1-1-1; p1-1; r1-1; tibia v2-2-2; r1-1; p1-1; metatarso v2-2; r1$1-1 ; \mathrm{p} 1-1-1$.

Patrón de coloración igual que en el macho, opistosoma sin escudo dorsal. Epiginio con dos orificios de cópula en la parte media. Espermatecas primarias mayores que las secundarias (Figs. 3 y 4 ).

Paratipos: Machos $(n=9)$. Longitud total 6.3-10.1. Caparazón 3.0-5.3 de longitud y 2.3-4.2 ancho. Fémur I 3.2-5.2. Hembras $(n=4)$. Longitud total 9.3-10.3. Caparazón 4.2-5.0 largo, 3.54.1 ancho. Fémur I 4.0-4.5.

Diagnosis.- El macho de C. comondensis es muy semejante al de $C$. bajulus, pero difiere en que en la segunda la ATR tiene un proceso ventral más corto; el PT aunque lobulado tiene diferente forma, la DAC del émbolo no está tan conspicuamente acanalada, la porción retrolateral del émbolo es más larga y puntiaguada. La forma del epiginio de C. comondensis es parecida a $C$. bajulus, pero difiere en que los orificios de cópula en la primera están más juntos y no presenta un septo transverso (Gertsch 1942, figs. 31 y 32).

Material examinado. Holotipo macho - México, Baja California Sur. San Isidro-La Purísima 26॰12' 23"N, 11202' 54"O, 291 m de altitud, 6 abril 2003. G. Nieto-Castañeda. CARCIB-0002 Alotipo hembra - Mismos datos que el holotipo. M. Correa-Ramírez. CARCIB-0003

Paratipos: México, Baja California Sur. San Isidro-La Purísima 7 machos, 1 hembra, 24 noviembre 2002, 14 diciembre 2002, 8 febrero 2003, 6 abril 2003, G. Nieto-Castañeda; San

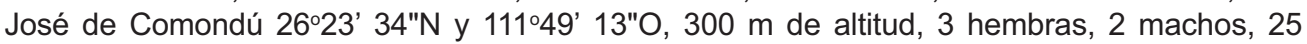
noviembre 2002, 10 febrero 2003 M. Correa-Ramírez y C. Palacios-Cardiel, 8 abril 2003, G. NietoCastañeda. Dos paratipos macho y hembra depositados en: CAS-ENT9023359; dos paratipos 
macho y hembra en CNAN-T0262 y nueve paratipos macho y hembra en CARCIB-0004.

Etimología. El nombre de Creugas comondensis sp. nov. se deriva del Municipio de Comondú, Baja California Sur, donde fueron encontrados los ejemplares.

Distribución.- Esta especie es conocida sólo para Baja California Sur.

Historia natural.- Los ejemplares fueron capturados en trampas de caída en suelos de ambientes húmedos con vegetación del tipo mezquite (Prosopis articulata S. Wats, 1889), otatabe [(Vallesia glabra (C.A.V.) Link, 1821], palo verde [Cercidium microphyllum (Torr.) Rosae \& Jhtn, 1924] y cítricos. También fueron encontrados en el matorral xerófilo dominado por mezquites, acacia Acacia farnesiana (L.) Wild, 1806, lomboyes Jathropha cuneata Wigg \& Rollins, 1943; «rama prieta» Ruellia californica (Rose) I. M.Smith, 1924, agaves (Agave spp), cholla (Opuntia spp), y «viejitos» (Mammillaria spp), seguida por árboles frutales y arbustos introducidos. Un total de 15 ejemplares hembras y machos fueron colectados de septiembre del 2002 a abril del 2003 en ambas localidades. Los adultos fueron más abundantes únicamente en abril y no se capturaron juveniles. Esta especie fue más común en la zona xérica de La Purísima.

\section{AGRADECIMIENTOS}

A G. Nieto, M. Correa y C. Palacios por su ayuda en la captura de especimenes. A los revisores anónimos por sus valiosos comentarios al manuscrito y a $\mathrm{O}$. Armendáriz por la realización de los contornos de los dibujos. Este trabajo fue apoyado por el Consejo Nacional de Ciencia y Tecnología (CONACyT) México y el proyecto SEMARNAT-2002-C01-005.

\section{LITERATURACITADA}

Bonaldo, A.B. 2000. Taxonomia da Subfamília Corinninae (Araneae, Corinnidae) nas regiõnes Neotropical e Neártica. Iberingia, Sér. Zool., Porto Alegre, (89):3-148-5.

Chamberlin, R.V. 1924. The spider fauna of the shores and islands of the Gulf of California. Proc. Califor. Acad. Sci. 12:678-694.

García, E. 1981. Modificaciones al sistema de clasificación climática de Köeppen. Instituto de Geografía. UNAM. México, D.F. 246 p.

Gertsch, W. J. 1942. New American spiders of the family Clubionidae, III. Amer. Mus. Nov. 1195:1-18.

Gertsch, W.J. \& L. I. Davis. 1940. Report on a Collection of Spiders from México. III. Amer. Mus. Nov. 1069:1-22.

Pickard-Cambridge, F. O. 1897. Arachnida-Araneida. Biol. Centrali-Americana. Lond. Vol. II p. 63-73.

Platnick, N. I. 2006. The world spider catalog, version 6.5. American Museum of Natural History, online at http://research.amnh.org/entomology/spiders/catalog/index.html

Ubick, D. \& D.B. Richman. 2005. Corinnidae. Pp 79-82. In: D. Ubick, P. Paquin, P.E. Cushing \& V. Roth (eds). Spiders of North America: an identification manual. American Arachnological Society, www.americanarachnology.org. 
